\title{
KAJIAN TENTANG PENANGANAN ILLEGAL FISHING DI TIMOR LESTE
}

\author{
Seguito Monteiro \\ Fakuldade Direito \\ Universidade Dili (UNDIL), Timor Leste \\ E-mail: s.monteiro_1981@yahoo.com
}

\begin{abstract}
ABSTRAK
Penelitian ini menggunakan penelitian hukum normatif, yang menekankan pada studi dokumen dalam penelitian kepustakaan untuk mempelajari data sekunder di bidang hukum yang berhubungan dengan permasalahan dan tujuan penelitian ini. Pendekatan yang digunakan adalah pendekatan konseptual dan pendekatan historis. Pendekatan konseptual dalam penelitian ini dimaksudkan untuk mencari kajian penanganan illegal fishing di Timor Leste yang berasal dari asas-asas hukum yang relevan. Pendekatan historis dilakukan dalam kerangkan pelacakan kasuskasus kejahatan Illegal Fishing di perairan Timor Leste. Penelitian ini menekankan pada data sekunder yang terdiri dari bahan hukum primer berupa ketentuanketentuan mengenai Kejahatan Illegal Fishing seperti dalam undang-undang dan sebagainya, sedangkan bahan hukum sekunder diperoleh dari buku teks, jurnal, kasus-kasus hukum. Prosedur pengumpulan bahan hukum dilakukan melalui studi literatur dan studi dokumen sesuai dengan permasalahan yang telah dirumuskan untuk selanjutnya dikaji secara komprehensif. Hasil penelitian menunjukkan bahwa dalam Hukum Nasional Timor Leste telah di atur dalam Dekretu Governu No. 5/2004 Juillu Regulamentu Jeral Peskas No Akikultura mengenai pelayaran di perairan Timor Leste dan pembatasan Zona Maritim nasional dalam hal ijin mengenai aktifitas kapal umum penangkap ikan di perairan nasional Timor Leste yang tertera pada Pasal 2 (1). Selanjutnya melalui pencegahan pelayaran kapal asing di perairan terluar dengan efek pencegahan dalam artian, operasinya dikonsentrasikan pada perairan potensial yang rawan dari ancaman kedaulatan, serta dapat dilakukan melalui preventif dan responsive dimana melalui sarana dan prasarana teknologi sisitem monitorining kapal.
\end{abstract}

Kata Kunci : Illegal Fishing, Penanganan,Timor Leste

\section{ABSTRACT}

This research used normative law study that emphasized document study in library research to study secondary data in law field related to problem and objective of the research. The research used conceptual and historical approach. Conceptual approach was intended to look for analysis of illegal fishing handling in Timor Leste based on relevant law norms. Historical approach was done in tracing illegal fishing cases in Timor Leste water. This research emphasizes secondary data consist of primary law matter such as provision on illegal fishing crime in form of laws and secondary law material from textbook, journal and law cases. Law material was collected through literature study and document study according to formulated problems and then analyzed comprehensively. Result of the research indicated that in Timor Leste National Law, the issue has been regulated in Dekretu Governu No. 5/2004 Juillu Regulamentu Jeral Peskas No Akikultural on shipping in Timor Leste waters and national Jurnal Komunikasi Hukum (JKH) Universitas Pendidikan Ganesha 
maritime zone limitation concerning license for catching ship activity in Timor Leste waters stipulated in Article 2 (1). Then, through prevention of foreign ship shipping in the outermost waters in which its operation was concentrated in water having potential of sovereignty threat and may be done through preventive and responsive way using ship monitoring system.

Keywords: illegal fishing, handling, Timor Leste

\section{Pendahuluan}

Timor Leste (Republica

Democratic de Timor Leste-RDTL) merupakan negara pantai dengan luas wilayah daratan $15.007 \mathrm{Km}^{2}$. Wilayah darat ini terdiri dari wilayah daratan di Distrik Oekusi-Ambenuk seluas 815 $\mathrm{Km}^{2}$ (Enklave ida iha Territóriu Indonézia) yang masuk wilayah Indonesia, di Pulau Atauru seluas 150,20 Km², dan di Pulau Jaco di ujung Timur seluas 12,00 $\mathrm{Km}^{2}$.http:/ / timorleste.gov.tl $/ p=547 \&$ lang=tp. Secara geografis, Timor Leste berada di kawasan Asia Tenggara, yaitu di Pulau Timor bagian Timur dengan koordinat 8.50' LS, 125.55' BT. http://www.kemlu.go.id/dili/id/. Perairan laut Timor Leste yang memiliki keanekaragaman kekayaan yang terkandung di dalamnya ini dinilai sangat potensial bagi pembangunan ekonomi negara. Oleh karena itu, untuk mengelola, menjaga, dan mengamankan wilayah perairan laut Timor Leste menjadi tanggung jawab yang besar bagi aparat Penegak hukum. Untuk mengamankan laut diperlukan kekuatan dan kemampuan yang memadai di bidang kelautan baik berupa peralatan dan teknologi serta sumber daya manusia yang handal maupun berupa ketentuan dan peraturan yang mengatur tentang kelautan.

Kekayaan ikan yang begitu besar harus dilindungi dari berbagai penangkapan ikan yang dilakukan secara ilegal (illegal fishing) oleh orangorang atau korporasi baik yang dilakukan warga negara Timor Leste maupun oleh warga negara asing. Berbagai kasus penangkapan ikan yang dilakukan secara ilegal yang dilakukan kapal-kapal asing yang berkewarganegaraan asing dengan berbagai modus operandi. Kapalkapal berbendera Timor Leste tetapi anak buah kapal tersebut seluruhnya berkewarganegaraan asing, seperti Unregulated fishing yaitu kegiatan penangkapan di perairan wilayah suatu negara yang tidak mematuhi aturan yang berlaku di negara Timor Leste yang mana tertangkapnya 15 kapal penangkap ikan asal China, oleh kapal Ocean Warrior yang berhasil menemukan di titk $150 \mathrm{~km}$ di perairan selatan Timor Leste. Kapal-kapal China yang dimiliki oleh perusahaan Pingtan Marine Enterprise tersebut, yang beroperasi dengan ijin dari Kementerian Pertanian dan Perikanan Timor Leste, yang akan berakhir pada bulan November tahun 2017, namun ijin tersebut disalah gunakan karena terbukti ribuan ekor ikan hiu di setiap kapal, sehingga melihat dari cara memasang jaring insang bawah yang pada dasarnya memberat ke dasar laut, seakan menangkap ikan, namun sangat jelas bahwa mereka hanya mencari ikan hiu," jelas Stokes. http://www.republika.co.id/ Namun dalam proses peradilan distrik Baucau akhirnya mengambil keputusan untuk

Jurnal Komunikasi Hukum (JKH) Universitas Pendidikan Ganesha 
melepaskan ke 15 kapal asal china ke negaranya dengan denda seratus ribu dollar amerika (USD 100,000,00). Jurnal TimorPost.tersa feira 12 junhu 2018.

Adanya penangkapan ikan hiu yang berlebih, pencurian ikan, dan tindakan illegal fishing lainnya yang tidak hanya menimbulkan kerugian bagi negara, tetapi juga mengancam kepentingan nelayan dan pembudi daya-ikan, iklim industri, dan usaha perikanan nasional. Permasalahan tersebut harus diselesaikan dengan sungguh-sungguh, sehingga penegakan hukum di bidang strategis dalam rangka menunjang pembangunan perikanan secara terkendali dan berkelanjutan. Dengan adanya kepastian hukum merupakan suatu kondisi yang mutlak diperlukan dalam penanganan tindak pidana di bidang perikanan.

Dengan demakin banyaknya kasus tindak pidana di bidang perikanan secara ilegal yang dilakukan oleh nelayan asing maupun nelayan Timor Leste, maka pemerintah Timor Leste harus melakukan upaya penegakan hukum untuk mencegah dan menanggulangi tindak pidana di bidang perikanan yang terjadi di wilayah laut Timor Leste.

Berdasarkan fenomena dan kondisi sebagaimana diuraikan di atas, dipandang perlu melakukan penelitian mengenai "Kajian Tentang Penanganan Illegal Fishing di Timor Leste". Mengingat permasalahan Illegal Fishing merupakan suatu masalah yang universal dan salah satu topik yang hangat didiskusikan dalam forum internasional maupun nasional maka penting untuk mengkaji perikanan menjadi sangat penting dan

bagaimana penanganan illegal fishing di Timor Leste.

\section{Metode Penelitian}

Penelitian merupakan usaha untuk menentukan, mengembangkan dan menguji kebenaran suatu pengetahuan. Theo Huijbers,1982:27. Penelitian ini menggunakan penelitian hukum normatif, yang menekankan pada studi dokumen dalam penelitian kepustakaan untuk mempelajari data sekunder di bidang hukum yang berhubungan dengan permasalahan dan tujuan penelitian ini. Pendekatan yang digunakan adalah pendekatan konseptual dan pendekatan historis. Peter Mahmud Marzuki, 2005:93 Pendekatan konseptual dalam penelitian ini dimaksudkan untuk mencari Kajian Penanganan Illegal Fishing di Timor Leste yang berasal dari asas-asas hukum yang relevan. Pendekatan historis dilakukan dalam kerangkan pelacakan kasus-kasus kejahatan Illegal Fishing di perairan Timor Leste.

Penelitian ini menekankan pada data sekunder yang terdiri dari bahan hukum primer berupa ketentuanketentuan mengenai Kejahatan Illegal Fishing seperti dalam dalam undangundang dan sebagainya, sedangkan bahan hukum sekunder diperoleh dari buku teks, jurnal, kasus-kasus hukum. Prosedur pengumpulan bahan hukum dilakukan melalui studi literatur dan studi dokumen sesuai dengan permasalahan yang telah dirumuskan untuk selanjutnya dikaji secara komprehensif. Pengolahan dan analisis bahan hukum dilakukan dengan cara memahami teks dari bahan hukum kemudian dikaitkan dengan isi pengertian teks yang satu dengan yang lain yang Jurnal Komunikasi Hukum (JKH) Universitas Pendidikan Ganesha 
menggambarkan tentang Kajian Penanganan Illegal Fishing di Timor Leste

\section{Pembahasan}

\section{Aktifitas Illegal fishing}

Aktivitas illegal fishing di perairan maritime Timor Leste yang selama ini bebas berkeliaran sehingga menjadi malasah nasional dan menjadi ancaman bagi keutuhan Negara Timor Leste. Dilihat dari perkembangan illegal fishing di tahun 2015 semakin meningkat. Dari kasus di atas telah diidentifikasi bahwa penangkapan ikan secara ilegal di perairan Laut Timor Leste kebanyakan kapal penangkap ikan illegal berasal dari luar negari.
Kegiatan illegal fishing kebanyakan terjadi di perairan antara perbatasan Lore, Iliomar, dan Uatu-Carbau, itu antara lain adalah pencurian ikan oleh kapal-kapal ikan asing yang berasal dari beberapa negara tetangga. Dari laporan kegiatan illegal fishing yang telah diinformasikan dan ditangani oleh Kementerian Kelautan dan Perikanan melalui Polisi Maritim dan angkatan laut Timor Leste, data dari Departemen Pertanian dan Perikanan tahun 2013 menghitung bahwa TimorLeste telah kehilangan kurang lebih setidaknya 30.600 .000 ton ikan (kecil dan besar no "ikan Demersal"), bernilai sekitar 214.500 .000 dolar setiap tahun. Data diambil di Departementu Inspesaun Jeral Sekretariu Estadu Peskas.15 Desember 2016.

\begin{tabular}{|c|c|c|c|c|c|}
\hline $\begin{array}{l}\mathbf{N} \\
\mathbf{o}\end{array}$ & Aktifitas Illegal & $\begin{array}{l}\text { Type } \\
\text { Ikan }\end{array}$ & Unit & \begin{tabular}{|l} 
Periode \\
\end{tabular} & Jumlah \\
\hline \multirow[t]{4}{*}{1} & Kapal ikan illegal & $\begin{array}{l}\text { Ikan } \\
\text { kecil }\end{array}$ & 30 Unit & $\begin{array}{l}\text { Satu } \\
\text { hari }\end{array}$ & $\$ 2.00 / \mathrm{kg}$ \\
\hline & Ikan yang ditangkap & & $\begin{array}{l}2.000 \\
\mathrm{~kg}\end{array}$ & $\begin{array}{l}\text { Satu } \\
\text { hari }\end{array}$ & \\
\hline & $\begin{array}{l}\text { Total ikan yang hilang akibat } \\
\text { illegal fishing }\end{array}$ & - & & Perthun & $\begin{array}{l}18.000 .00 \mathrm{~kg}(18.0 \\
0)\end{array}$ \\
\hline & Kerugian akibat illegal fishing & - & & $\begin{array}{l}\text { Pertahu } \\
\mathrm{n}\end{array}$ & $\begin{array}{l}\$ 36.000 .000 / \mathrm{Th} \\
\mathrm{n}\end{array}$ \\
\hline \multirow[t]{4}{*}{2} & Kapal ikan ilegal & $\begin{array}{l}\text { Ikan } \\
\text { Besar }\end{array}$ & 30 unit & Perhari & \\
\hline & Ikan yang ditangkap & & $200 \mathrm{~kg}$ & Perhari & $\$ 25.00 / \mathrm{kg}$ \\
\hline & $\begin{array}{l}\text { Total ikan yang hilang akibat } \\
\text { illegal fishing }\end{array}$ & & & $\begin{array}{l}\text { Pertahu } \\
\mathrm{n}\end{array}$ & $\begin{array}{l}\$ 2.100 .000 \\
\operatorname{kg}(2.100 \mathrm{~T}\end{array}$ \\
\hline & Kerugian akibat illegal fishing & & & $\begin{array}{l}\text { Pertahu } \\
\mathrm{n}\end{array}$ & $\$ 52.500 .00 /$ Thn \\
\hline 3 & Kapal ikan ilegal & $\begin{array}{l}\text { Ikan } \\
\text { Deme } \\
\text { rsal }\end{array}$ & 30 unit & Perhari & \\
\hline & Ikan yang ditangkap & & $\begin{array}{l}1.000 \\
\mathrm{~kg}\end{array}$ & & $\$ 12.00 / \mathrm{Kg}$ \\
\hline
\end{tabular}

Jurnal Komunikasi Hukum (JKH) Universitas Pendidikan Ganesha 


\begin{tabular}{|l|l|l|l|l|}
\hline $\begin{array}{l}\text { Total ikan yang hilang akibat } \\
\text { illegal fishing }\end{array}$ & & $\begin{array}{l}\text { Pertahu } \\
\mathrm{n}\end{array}$ & $\begin{array}{l}10.500 .00 \mathrm{~kg}(10.5 \\
00 \mathrm{t})\end{array}$ \\
\hline Kerugian akibat illegal fishing & & & & $\begin{array}{l}\text { US\$ } \\
126.000 .000 / \text { thn }\end{array}$ \\
\hline $\begin{array}{l}\text { Total ikan yang hilang akibat } \\
\text { illegal fishing }\end{array}$ & & $\begin{array}{l}\text { Pertahu } \\
\mathrm{n}\end{array}$ & 30.600 .000 Ton \\
\hline & Total kerugian uang yang hilang & & & $\$ 214.500 .000$ \\
\hline
\end{tabular}

Sumber: Peska Ilegal: Ameasa no Obstaklu ba Instituisaun Siguransa. Mahein Nia Lian Nú 69, 13 Fevereiru 2014

Menurut perhitungan kementrian Pertanian dan Perikanan Timor Leste (Ministeriu Agrikultura no Peskas) bahwa tiap tahun tinan TimorLeste, rugi akibat kegiatan illegal fishing diperairan nasiona sehingga total kerugian yang dialami oleh Timor Leste setiap tahun adalah 30.600,000 ton/ pertahun Aktifitas illegal fishing ini memberikan dampak yang sangat besar bagi perekonomian Timor Leste apabila terus berjalan di daerah perairan zona maritime untuk tetap melakukan ekslorasaun kekayaan.

Kegiatan illegal fishing dari tahun 2006 sampai sekarang kurang lebih kapal asing yang melakukan penangkapan ikan secara illegal diperairan wilayah maritime Timor Leste sebanyak 30 kapal yang melakukan operasi penangkapan ikan ilegal di Laut Timor Leste, terutama di area lepas Pantai Selatan Lore, Laivai, Tutuala Lautem, serta Uatucarbau Kabupaten Viqueque. Di tahun 2011, dari kasus di atas antara bulan Juli dan Agustus, setidaknya 25 kapal penangkap ikan ilegal juga mencuri ikan perairan antara Iliomar dan Uatucarbau. Dari 12 kapal ilegal ditangkap oleh pasukan angkatan laut (FFDTL Naval) pada tahun 2013. Data diambil tgl 20 -12-2015. dari Polisia maritima Timor Leste.involve-peskailegal-sidadaun-estranjeiru-naval-

kaer.dapat dilihat pada gambar dibawah ini.

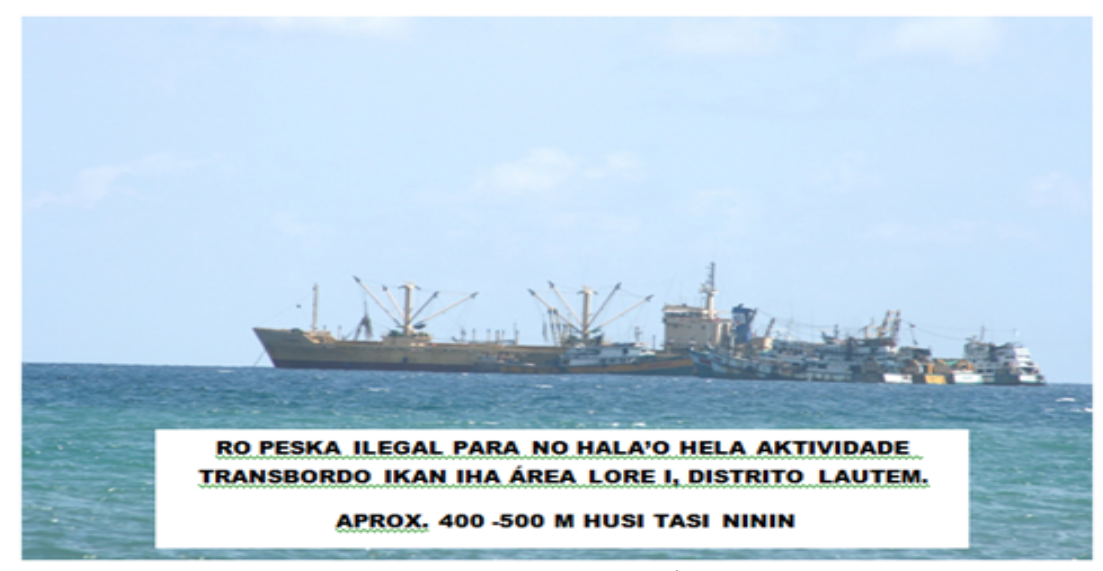

Gambar 1: Kegiatan illegal Fishing transfer ikan di Laut Timor Leste area Lore I Distritu Lautem

Jurnal Komunikasi Hukum (JKH) Universitas Pendidikan Ganesha 
Pengaturan Perundang-undangan Nasional yang Relevan dengan Penanganan Illegal Fishing di Timor Leste

Timor Leste mempunyai hak berdaulat, yurisdiksi dan kewajibankewajiban atas sumber daya yang ada di ZEEI. Dalam rangka melaksanakan hak berdaulat, hak-hak lain, yurisdiksi dan kewajiban-kewajiban, aparatur penegak hukum Timor Leste yang berwenang, dapat mengambil tindakan-tindakan penanganan hukum sesuai dengan Hukum acara pidana Timor Leste Código Do Processo Penal bagian III mengenai Pasal 17 (1) dimana kejahatan dilakukan di atas kapal atau pesawat terbang yang mengatakan bahwa kejahatan yang dilakukan di atas kapal atau di pesawat, pengadilan di wilayah tersebut yang mengadili pelaku tidak pidana Artigo 17. ${ }^{\circ}$ Crime cometido a bordo de um navio ou de aeronave 1. É competente para conhecer de crime praticado a bordo de navio ou deaeronave, o tribunal em cuja área se situe o local onde o agente desembarcar. Código Do Processo Penal. 2006:152

Berdasarkan Kitab Undangundang hukum Pidana Timor Leste Pasal 219 (1) mengatakan bahwa Penangkapan ikan ilegal adalah mereka yang menangkap ikan di perairan maritim nasional tanpa izin dimana penangkapan ikan yang layak yang diperoleh dari otoritas administratif yang kompeten akan dihukum dengan hukuman penjara hingga 3 tahun atau denda. Artigo $219^{\circ}$ Pesca illegal 1. Quem pescar em águas marítimas nacionais sem a devida licença de pesca obtida junto da entidade administrativa competente, é punido com pena de prisão até 3 anos ou multa. Código Penal,2009:124. Terlihat bahwa rangkain kegiatan mulai dari pengelolaan sampai pemasaran ikan merupakan satu kesatuan yang tidak dipisahkan dan diatur oleh kitap Undang-undang hukum Acara Pidana maupun Kitap Undang-undang Hukum Pidana Código Penal tersebut serta Peraturan Pemerintah No 5 Tahun 2004 tentang Pengaturan Umum Perikanan dan Pertanian (Repúblika Demokrátika Timor-Leste Dekretu Governu No. 5/2004 Juillu Regulamentu Jeral Peskas No Akikultura).

Selanjutnya sektor pelayaran di perairan Timor Leste semakin berkembang, oleh karena itu Timor Leste lewat Kementrian Pertanian, Kehutanan dan Perikanan Timor Leste telah melakukan pembatasan Zona Maritim nasional dalam hal ijin mengenai aktifitas kapal umum penangkap ikan di perairan nasional Timor Leste yang tertera pada Pasal 2 (1) mengenai zona penangkap ikan: dimana akan memberikan ijin secara umum kepada para nelayan untuk menagkap ikan sebagai beriku di mana di zona A diukur 200 meter dari wilayah territorial, zona B diukur 3 N.M dari batas laut teritorial yaitu bagian utara dan bagian selatan, zona C diukur dari 12 N.M dari batas laut teritorial nasional untuk area industri perikanan nasional yaitu di bagian selatan, untuk zona D diukur 16 N.M dari batas laut teritorial nasional itu sebagai area untuk semi industri perikanan luar negeri yaitu di bagian selatan dan yang terakhir yaitu zona $\mathrm{E}$ yang diukur dari 18 N.M dari batas laut teritorial nasional untuk industri perikanan luar negeri dibagian selatan. 1(Lisensa ba peska komersial bele fo deit ba zona be maritma nasional hirak tuir mai ne'e) :

Jurnal Komunikasi Hukum (JKH) Universitas Pendidikan Ganesha 
a. Zona A sukat metro 200 hosi kosta territoriu nasional nian, ba peska artesana nasional(kosta norte ho sul / tasi feto ho tasi mane)

b. Zona B, sukat nautiku (mn) 3 mn hosi kosta territoriu nasional nian (kosta norte ho sul):

c. Zona C,sukat millas nautiku (mn)12 hosi kosta territoriu nasional nian, ba peska industria nasional (kostal sul/ tasi mane):

d. Zona $D$, sukat millas nautiku (mn) 16 hosi kosta territoriu nasional nian, ba peska semi - industria estranjeiru (kostal sul / tasi mane):

e. Zona E, sukat millas nautiku (mn) 18 hosi kostal territoriu nasional nian, ba pekas industria estranjeiru (kostal sul / tasi mane).

Membahas penangkapan ikan secara ilegal (illegal fishing) tidak terlepas dari struktur penegakan hukum di laut, yaitu instansi dan aparat penegak hukum di laut. Dalam rangka koordinasi dan sinkronisasi kebijakan penegakan hukum di laut maka penanganan isu kedaulatan maritim secara berkelanjutan maka perlu dibangun kerangka regulasi. berkaitan erat dengan peraturan perundang - undangan yang mengatur mengenai laut dan segala aktivitas yang terhubung dengan laut. Ini mengingat aspek kelautan Timor Leste menyimpan potensi yang sangat besar sehingga melibatkan banyak stakeholders yang diberikan wewenang terhadap laut Timor Leste dan pengaturannya tersebar dalam beberapa peraturan perundangundangan yang diberlakukan di yurisdiksi laut nasional tersebut, antara lain:

1) Kerangka regulasi yang perlu dibangun secara umum merupakan penjabaran/amanat Konstituisaun
Repúblika Demokrátika Timor-Leste (RDTL 2002) dan República Democrática De Timor-Leste Parlamento Nacional, Lei N.O 7/2002 De 20 De Setembro Fronteiras Maritimas do Territorio Da Republica Democratica De Timor-Leste serta Peraturan Pemerintah, maupun peraturan lain yang diperlukan dalam operasional/implementasi kebijakan.

2) República Democrática De Timor-Leste Dekretu - Lei Governu N. ${ }^{\circ}$ 6/2004 21 Abril 2004 Baze Jeral Rejime Jurídiku Ba Jestaun Ho Ordenamentu Peska Ho Akikultura Nian.

3) Unang-Undang (Lei) Nomor 12 tahun 2004 "Krime Relatiou Ho Peska"

4) Knar Geral Policia Nasional Timor Leste E Lei Organiku (Decreto Lei No.09/2009 Dia 18 De Fevereiro) Undang-undang Kepolisian Timor Leste

5) Peraturan perundang-undangan yang ada mengenai penegakan hukum di perairan Timor Leste belum mengakomodasi dan mengantisipasi perkembangan dan permasalahan yang timbul, termasuk perkembangan teknologi yang diperlukan dalam rangka penegakan hukum di laut. Dilihat dari landasan hukum penegakan hukum di perairan Timor Leste yang di muat dalam undangundang nomor 7 tahun 2002 belum cukup memadai.

6) Kerangka Regulasi dalam penegakan hukum dimana kemampuan para aparat penegak hukum diperairan Timor Leste tidak memadai, termasuk kemampuannya dalam penguasaan terhadap peraturan perundangundangan yang berkaitan dengan 173

Jurnal Komunikasi Hukum (JKH) Universitas Pendidikan Ganesha 
penegakan hukum diperairan Timor Leste, baik zona territorial zona tambahan dan zona Zona Ekonomi Eksklusif. wawancara dengan para pihak anggota Polisi Maritim Unidade Policia Maritima (UPM) dan angkatan laut Forças de Defesa de Timor Leste NAVAL ( FFDTL) maupun Kementrian Perikanan Timor Leste dinyatakan bahwa kemampuan para aparat penegak hukum tidak memadai, karena pada umumnya mereka kurang dibekali pendidikan dan pelatihan teknis serta diklat pegawai negeri sipil sesuai dengan bidang instansi masing-masing. Jika kemudian terjadi penanganan penegakan hukum di perairan Timor Leste baik di zona territorial, zona tambahan dan ZEE yang tidak optimal, hal ini disebabkan masalah koordinasinya yang belum berjalan sebagaimana mestinya seperti dijelaskan di atas.

Undang-undang tersebut dapat dikategorikan menjadi dua, yaitu pertama, undang-undang yang bersifat umum, seperti Konstitusi mengenai Wilayah Negara, kedua, undang-undang yang seluruhnya mengatur laut, seperti UndangUndang no 7 tahun 2002 mengenai batas maritim, Undang-udang tentang Perikanan, serta Lei Organiku (Decreto Lei No.09/2009 Dia 18 De Fevereiro) Undang-undang Kepolisian Timor Leste.

Regulasi tersebut memberikan kewenangan kelembagaan untuk menegakan hukum di laut pada beberapa instansi sesuai dengan materi muatan yang diatur dalam undang-undang itu. Pengaturan kewenangan tersebut antara lain sebagai berikut: a) Konstituisaun Repúblika Demokrátika Timor-Leste (RDTL 2002) bahwa wilayah perairan Timor Leste meliputi laut teritorial Timor Leste, perairan pedalaman, serta ruang udara di atas laut teritorial dan perairan pedalaman, serta dasar laut dan tanah di bawahnya, termasuk sumber kekayaan alam yang ada di dalamnya. Penegakan kedaulatan hukum di perairan Timor Leste, ruang udara di atasnya, dasar laut dan tanah di bawahnya termasuk kekayaan alam yang terkandung di dalamnya serta sanksi atas pelanggarannya dilaksanakan sesuai dengan ketentuan konvensi hukum internasional dan peraturan perundang-undangan yang berlaku di Timor Leste.

b) Undang - undang no $7 / 2002$ tentang perbatasan maritim Timor Leste tentang kewenangan untuk menegakan hukum dan kedaulatan negara kepada Polisi Maritim dan FFDTL Naval. Untuk melaksanakan hak berdaulat, yurisdiksi, hak-hak lain, dan kewajiban-kewajiban berdasarkan Konvensi Hukum Laut yang berlaku sebagaimana diatur dalam Pasal 10 ayat (1-5) Undang-undang tentang hak berdaulat dan yurisdiksi, aparat penegak hukum Timor Leste yang berwenang dapat mengambil tindakan penegakan hukum sesuai dengan Konstitusi. Lei N.O 7/2002 frontera maritima.

c) Konstitusi Timor Leste mengatakan bahwa pertahanan negara disusun dengan memperhatikan kondisi geografis dimana mengamanatkan bahwa Forças de Defesa de Timor Leste NAVAL F-FDTL) bertanggungjawab untuk

Jurnal Komunikasi Hukum (JKH) Universitas Pendidikan Ganesha 
melindungi negara dari serangan luar ini tercantum dalam Konstitusi Timor Leste Artigu 146 (1,) menyatakan bahwa "Forsa Armada Timór-Leste nian, FALINTIL/FDTL, ne'ebé sidadaun nasionál de'it maka halo parte, ne'e mak responsavel ba defeza militár Repúblika Demokrátika Timór-Leste nian no nia organizasaun nu'udar ida mesak ba territóriu nasionál tomak." Angkatan Pertahanan Timor Leste, FALINTIL-FDTL, yang hanya terdiri atas warga negara nasional, bertanggung jawab atas penyediaan pertahanan militer bagi Republik Demokratis Timor Leste dan akan memiliki sistem penataan tunggal untuk seluruh wilayah nasional.

Selain itu, Undang-undang ini juga menentukan bahwa Polisi Maritim Timor Leste, (Unidade Policia Maritima UPM) berperan sebagai sistem utama pertahanan negara yang salah satu tugas pokoknya menegakan kedaulatan negara, keutuhan wilayah Timor Leste, serta melindungi wilayah perairan Timor Leste dari ancaman dan gangguan terhadap bangsa dan negara Pasal 32 ayat (1) yang menyatakan bawah polisi maritim diberi kewenangan khusus seccara system integral dengan angkatan keamanan lainya, serta memberikan pelatihanan secara special untuk melakukan pengawasan di daerah maritm yang telah di tentukan berdasarkan peta. Dekretu -Lei n. 16/2009, Lei Organika Polísia Nasionál Timor-Leste (PNTL).

d) Undang-undang Imigrasi No.9 Tahun 2003 memberikan kewenangan penegakan hukum kepada departemen imigrasi diserah terimakan dari alfandegas (bea cukai) menjadi Departemen Imigrasi Timor Leste dengan perubahan pengontrolan yang semula dari perspektif sipil ke perspektif kepolisian. Salah satu implementasi dari pengontrolan Departemen Imigrasi adalah sebuah instrumen mengenai profesi aplikasi dalam kepolisian yang telah diterapkan dalam Negara Demokratik Timor Leste dan hal tersebut sudah menjadi kebijakan dari departemen tersebut untuk mengontrol warga negara asing yang menetap di Timor Leste dan juga untuk mengontrol arus perjalanan darat, udara, dan laut. Kewenangan keimigrasian Timor Leste memberikan izin masuk kepada warga asing yang akan masuk dan tinggal di teritori nasional dengan memberikan tanda ijin masuk dan mempersilakan warga asing keluar dari wilayah teritorial Timor Leste dengan memberikan ijin keluar yang terdapat dalam paspor pengunjung.

Undang-undang yang berlaku di laut tersebut telah memberikan pengaturan dan kewenangan hukum dari masing-masing instansi, namun belum terkoordinir dengan baik, dikarenkan belum ada undang undang kelautan yang lengkap, sehingga kewenangan stakeholders, saling bertentangan. Wawancara dengan wakil komandan Servisu Investigasaun Criminal (SIC),2 juli 2019. Regulasi di bidang kelautan tersebut belum dilaksanakan secara efektif dan efisien serta belum ada keterpaduan di antara undang- 
undang sektoral bidang kelautan, sehingga terkadang saling berbenturan dalam pengaturan hukum dan kewenangan kelembagaan yang bertanggung jawab di laut. Oleh karena itu, diperlukan harmonisasi sistem hokum dan peraturan perundang-undangan untuk terciptanya keamanan laut di wilayah yurisdiksi laut Timor Leste, mengkompilasi dan menghimpun peraturan perundang-undangan yang telah ada agar lebih memudahkan acuan dalam penegakan hukum di laut, dan membuat database peraturan perundang-undangan. Selain itu, juga sangat dibutuhkan suatu kebijakan dan peraturan kelautan Timor Leste yang komprehensif dan mengatur otoritas di laut sebagai perwujudan dari system pemerintahan yang baik dan bersih (good and clean governance).

Kebijakan dan peraturan kelautan tersebut harus berbentuk undang-undang agar mempunyai kekuatan hukum mengikat secara nasional dengan memuat dasar filosofis, sosiologis, dan yuridis yang disesuaikan dengan konsepsi geopolitik dan kebutuhan hukum negeri ini. Ini dimaksudkan untuk mengintegrasikan peraturan perundangun dangan yang sifatnya sektoral dan berlaku di wilayah perairan laut Timor Leste. Oleh karena itu, untuk memberikan solusi terhadap persoalan Timor Leste dalam keamanan maritim ini, perlu disusun regulasi dalam bentuk perundangundangan yang di dalamnya mengandung aspek pertahanan dan keamanan di laut yang meliputi :

1) Pertahanan dan keamanan secara terpadu di wilayah perbatasan dengan negara tetangga

Jurnal Komunikasi Hukum (JKH) Universitas Pendidikan Ganesha
2) Pengembangan sistem monitoring.

3) Pengamanan wilayah perbatasan dengan negara tentanga antara Australia dan Indonesia

4) Koordinasi keamanan dan penanganan pelanggaran di laut.

Selain substansi tersebut, regulasi ini perlu mengatur juga tentang pihak yang bertanggung jawab, bentuk kelembagaan, dan kewenangan hak untuk melakukan penyelidikan dan penyelidikan terhadap pelanggaran hukum yang terjadi di laut.

\section{Penanganan Illegal Fishing di wilayah Laut Timor Leste}

Kegiatan illegah fishig oleh nelaya asing dilakukan oleh Negara - Negara tetangga di kawasan yang memasuki perairan Timor Leste secara illegal. Penangkapan ikan secara illegal tersebut telah merugikan Negara secara ekonomi, data dari Departemen Perikanan Timor Leste menunjukkan bahwa sejak tahun 2013 akhir dan masuk tahun 2014 awal, kerugian Timor Leste per tahun akibat illegal fishing mencapai $\$ 214.500 .000$, dan kerugian ikan per mencapai 30.600 .000 ton/ tahun. https://timordata.info/media/public ations/FM_MNL_69.pdf. Jumlah kerugian ini tidak sedikit. Selain itu, praktik illegal fishing juga berdampak pada berkurangnya stok sumber daya ikan dan hilangnya kesempatan para nelayan yang beroperasi secara legal, serta dapat mengakibatkan menurunnya ketahanan pangan. Illegal fishing di perairan Timor Leste menjadi masalah yang besar dan sangat merugikan masyarakat Timor Leste. Oleh karena itu, dibutuhkan tindakan yang tepat dalam menangani 
masalah tersebut. Menurut Lino Saldhana, nelayan asing yang sering melakukan penagkapan ikan secara illegal diperiran Timor Leste adalah Negara Indonesia tapi hanya bersakala kecil, tetapi Cina yang selama ini melakukan aktifitas illegal fishing di perairan laut Timor cukup besar.

Illegal Fishing terjadi di perairan Timor Leste itu dikarenakan potensi sumber daya perikanan yang besar, juga dikarenakan posisi geografis dari kawasan perairan Timor Leste yang berada di perairan perbatasan atau berdekatan dengan perairan Indonesia dan juga perairan Australia, dimana secara peralatan untuk mengawasi laut kurang memadai sehingga para nelayan asing memanfatkan situasi ini untuk melakukan penangkapan ikan secara illegal. Illegal fishing yang terjadi di perairan Timor Leste tersebut dapat digolongkan sebagai transnational crime atau tindak pidana lintas negara, karena pelakunya adalah orang asing atau orang Timor Leste tetapi melibatkan pihak asing dibelakangnya. intervista iha Ministeriu Agrikultura no Peskas Diresaun Geral Peskas, sevi departementu peskas 2018. Kegiatan illegal fishing tersebut biasanya beroperasi di wilayah perbatasan perairan Laut Timor bagian Barat dan bagian Timur yang sekarang belum ditentukan batas maritim antara Timor Leste dan Indonesia. Berdasarkan hasil penelitian yang dilakukan peneliti maka ditemukan beberapa faktor yang menyebabkan terjadinya Illegal fishing di perairan Timor Leste tidak terlepas dari faktor perbatasan dan belum adanya aturan delitimasi antara Negara-negara yang saling berhadapan atau berdampingan serta faktor lingkungan strategis global terutama kondisi perikanan di Timor Leste itu sendiri. Secara garis besar faktor penyebab tersebut dapat dikategorikan menjadi 6 (enam) faktor, sebagaimana diuraikan di bawah ini. Laporan Ministério $D a$ Agricultura E Pescas Secretariado De Estado Das Pescas Direç̧ão Nacional De Pescas E Aquicultura. Ezistensia Peska Ilegal Iha Tasi Teritoriu Timor-Leste. 2013:9:

a) Kebutuhan sumber bahan baku di negara pelaku illegal fishing sudah menipis akibat praktik industrialisasi kapal penangkapnya sehingga daya tumbuh ikan tidak sebanding dengan jumlah yang ditangkap, dan sebagai akibatnya, mereka melakukan ekspansi hingga ke wilayah perairan Timor Leste;

b) Lemahnya Pengawasan Polisi Maritim dan angkatan Laut (FFDTL NAVAL) di perairan laut Timor Leste, adalah salah satu faktor penyebab maraknya kasus illegal fishing yang banyak terjadi di perairan laut Timor Leste saat ini, dikarenakan kapal yang dimiliki oleh angkata laut dan polisi maritim Timor Leste yang sekaran digunakan adalah kapal yang berukurang kecil sehingga sulit untuk mengejar para pelaku illegal fishig diperairan laut Timor Leste.

c) Sisitem Monitorining Kapal. Salah satu upaya pengawasan dari pihak kementrian pertanian dan perikanan

Jurnal Komunikasi Hukum (JKH) Universitas Pendidikan Ganesha 
(Ministério da Agricultura e Pescas, liu husi Secretariado Estado das Pescas), dengan adanya bantuan dari Regional Fisheries Livelihood Programme (RFLP-FAO) yang sudah memasang SPOT TRACKER di dua kapal industri perikanan dan kapal ikan sejumlah 14 kelompok (peska artesanal hamutuk unidade 14 iha teritoriu Timor- Leste). Satellite Personnal Tracker (SPOT) sebagai cara untuk transmisi informasi dimana ada kegiatan illegal fishing itu terjadi dan juga menginformasikan ketika ada kapal yang berlayar diperairan laut Timor Leste mengalami kecelakaan. Namun Satellite Personnal Tracker (SPOT) yang sekarang digunakan belum memenuhi standar untuk ukuran perairan Laut Timor Leste.

d) Terbatasnya dana untuk operasional pengawasan, baik dari departemen kelautan, Polisi Maritima dan Angktan Laut Timor Leste (NAVAL)

e) Terbatasnya tenaga polisi perikanan dan Penyidik Pegawai Negeri Sipil di Departemen kelautan atau perikanan;

f) Kemampuan kapal dan alat komunikasi yang canggih oleh kapal asing, sehingga bisa memantau kelemahan setiap gerak kapal patrol Timor Leste yang kurang memadai diperairan Laut Timor

Permasalahan-permasalahan diatas, apabila tidak diantisipasi dapat berkembang menjadi sebuah ancaman yang membahayakan kedaulatan
Timor Leste. Untuk itu Polisi Maritim Unidade Policia Maritima (UPM) juga bekerja sama dengan tentara angkatan laut Forças de Defesa de Timor Leste NAVAL ( F-FDTL) selain menjalankan tugas-tugas pertahanan laut, juga berupaya melakukan strategi terpilih melalui kegiatan-kegiatan pro-aktif demi meningkatkan ketahanan nasional di wilayah atau kawasan perbatasan yang sesuai dengan kebijakan pemerintah. Kawasan perbatasan negara termasuk dua pulau kecil atauru, Zaco dan daerah Enclave Oecusi sebagai terdepan termasuk dalam kawasan strategis dari sudut kepentingan pertahanan dan keamanan nasional.

Berikut koordinasi instansiinstansi nasional yang bekerjasama dalam pengamanan laut dan pengelolaan sumber daya perikanan sebagai pelaksana teknis tindak pidana di lapangan :

1) Polisi Maritim Timor Leste, (Unidade Policia Maritima UPM), dan angkatan laut Forças de Defesa de Timor Leste NAVAL (F-FDTL).

Dalam proses penegakan hukum yang dilakukan oleh aparat penegak hukum dihadapkan pada beberapa permasalahan seperti kurangnya sumber daya, terbatasnya dukungan anggaran, kurangnya keterpaduan dan adanya visi unsur penegak hukum yang berbeda-beda. Namun demikian dalam rangka penegakan hukum di perairan wilayah Timor Leste pada umumnya, Polisi Maritim Unidade Policia Maritima (UPM) dan Forças de Defesa de Timor Leste NAVAL (F-FDTL) mempunyai peran yang cukup besar sehingga keberadaannya diharapkan dapat mengemban misi yang jelas guna 
lebih efektifnya pelaksanaan penegakan hukum.

Dengan memperhatikan uraian diatas maka misi penegakan hukum dalam rangka meningkatkan penegakan hukum diwilayah Timor Leste berdasarkan peraturan PNTL (Polícia Nacional de Timor-Leste ) adalah Kepolisian Nasional di Timor-Leste yang bertanggunjawab atas keamanan dalam negeri dan di bawah Kementerian dalam Negeri (Ministério do Interior). Pada pemerintahan sebelumnya PNTL di bawah Kementerian Pertahanan dan Keamanan (Ministério da Defesa e Segurança) khususnya Sekretariat Negara urusan Keamanan (Secretaria de Estado da Segurança).

Tugas dan funsgsi Unidade Policia Maritima (UPM) berdasarkan pada konstitusi Artigu 147. ${ }^{\circ}$ (Polísia no forsa seguransa sira) yang artinya bahwa Polisi akan membela keabsahan demokratis dan menjamin keamanan dalam negeri bagi semua warga negara dan akan bersifat sama sekali tidak memihak, tugas polisi juga untuk melakukan pencegahan kejahatan wajib dilaksanakan dengan tetap menghormati hak-hak asasi manusia, dan yang terakhir adalah Undang-undang akan menetapkan aturan dan peraturan bagi kepolisian dan angkatan keamanan lainnya, serta Peraturan Polisia Nasional Timor Leste Pasal 32 ayat (1-2) menyatakan bahwa Unit Polisi Maritim yang mana sistemnya secara terpusat dengan aparat maritime sehingga monitoring di area-area yang menjadi area pelayaran umum.
Polisi Maritim Unidade Policia Maritima (UPM) juga bekerja sama dengan tentara angkatan laut Forças de Defesa de Timor Leste NAVAL ( F-FDTL) sebagai satu sistem untuk menjaga laut nasional. Dekretu -Lei n. ${ }^{\circ}$ 16/2009, Lei Organika PNTL. 1). Polisi maritim diberi kewenangan khusus seccara sistem integral dengan angkatan keamanan lainya, serta memberikan pelatihanan secara special untuk melakukan pengawasan di daerah maritm yang telah di tentukan berdasarkan peta. 2). Komandan Polisi Maritim itu di lantik oleh Komandan Geral Polisi Nasional Timor Leste (PNTL), sesuai dengan pendidikan dan spesialis di area maritm:

a) Mencegah dan mengurangi kejahatan, khususnya kejahatan Narkoba, Illegal fishing, penjualan manusia, serta kejahatan Teroris.

b) Pencegahan untuk mengurangi masuknya imigran gelap

c) Menjaga keamanan wilayah perairan

d) Melakukan pengawasan dan melindungi kekayaan yang ada di dalam laut

e) Pencegahan dan melidungi pencemaran dilaut

f) Menyelamatkan manusia yang terdampar di laut

g) Perlindungan masyarakat di laut pedalaman

h) Melindungi kesehatan masyarakat

i) Melakukan perjalanan di seluruh wilayah maritime, dengan melakukan kordinasi atau kerjasama antara institusi 
yang saling terkait khususnya angkatan laut Forças de Defesa de Timor Leste NAVAL ( FFDTL)

j) Lewat kerjasama dengan pusat pelatihanan Polisi untuk menentukan keperluan atau program untuk melakukan pengarahan secara spesifik atau secara detail kepada mereka.

\section{Ministério da Agricultura e Pescas}

Terbentuknya Perikanan

(Ministério da Agricultura e Pescas), ini menempatkan sektor kelautan dan perikanan sebagai salah satu sektor yang mampu meningkatkan perekonomian negara, namun dalam proses pelaksanaannya terdapat isuisu dan hambatan-hambatan. Kementerian Kelauatan dan Perikanan sebagai perumus dan pelaksana kebijakan pemerintah di bidang perikanan. Dalam upaya penegakan hukum di bidang perikanan memiliki kerangka pembangunan sistem sumber daya kelautan dan perikanan untuk menekan seminimal mungkin pelanggaran IUU Fishing. Melalui perangkat hukum adanya aturan mengenai kementrian pertanian dan Perikanan (Ministério da Agricultura e Pescas) telah dibentuk melalui Undang-Undang Lei Nomor 12 tahun 2004 "Krime Relativu Ho Peska" pelanggaran terhadap penangkapan ikan dan Dekretu Governu N. 5/2004 Juillu Regulamentu Jeral Peskas No Akikultura peraturan pemerintah mengenai peraturan umum kementrian perikanan Timor Leste secara garis besar.

Untuk mencapai target pengurangan aktifitas IUU Fishing di wilayah perairan Timor Leste, berbagai kebijakan strategis telah dikembangkan dalam rangka ratifikasi UNCLOS 1982 serta berkaitan dengan pengawasan dan pengelolaan sumber daya kelautan khususnya perikanan, Untuk mencapai target pencapain kebijakan terdapat strategi-strategi diantaranya : Strategi Preemtive adalah pencegahan offensif sebelum terjadinya pelanggaran wilayah dan Responsive adalah reaksi cepat dalam menangani pelanggaran tindak pidana, Persuasive adalah pembinaan terhadap pelaku untuk meningkatkan kesadaran tidak melanggar hukum, dan melakukan koordinasi dengan instansi terkait Polisi Maritim Timor Leste, (Unidade Policia Maritima UPM), Forças de Defesa de Timor Leste NAVAL (F-FDTL):

\section{a) Strategi Preemtive.}

Strategi Preventive ada berbagai cara, seperti: melalui pencegahan pelayaran kapal asing di perairan terluar dengan efek pencegahan. Dalam artian, operasinya dikonsentrasikan pada perairan potensial yang rawan dari ancaman kedaulatan, antara lain Selat Ombai terletak di sebelah utara Oecusse yang memisahkan Oecusse di sebelah Barat Timor Leste dengan Pulau Alor dan Pantar yang merupakan bagian dari Propinsi Nusa Tenggara Timur Indonesia yang menghubungkan antara laut Banda dibelahan utara ke laut sawu kearah barat daya. Pulau pulau yang dipisahkan antara lain Enclave Oecusi Timor Leste dan Pulau Batek disebelah selatan dan Pulau Alor dan Pantar Tengah dan Teluk Mutiara, sedangkan di bagian selatan adalah kecamatan Amfoang Timur di kabupaten Kupang Timor Tengah Jurnal Komunikasi Hukum (JKH) Universitas Pendidikan Ganesha 
Utara, Selat Wetar (Wetar Strait) Selat Wetar adalah selat yang memisahkan bagian Timur dari pulau Timor dengan pulau Wetar. Selat ini berada di antara Pulau Wetar, Propinsi Maluku Indonesia (utaranya) dan Dili, Timor Leste (selatannya). Di sebelah baratnya ada Pulau Atauro, Timor Leste dan sebelah timur melalui wilayah laut anatara Pulau Kisar dan Leti Indonesia di sebelah utara dan Pulau Jaco Timor Leste di sebelah selatan. Wilayah ini juga menghubungkan Laut Banda di bagian Utara ke Laut Sawu di arah Barat daya. https://id.wikipedia.org/wiki/Selat_ Wetar Dan Laut Timor (Timor Sea) adalah perpanjangan dari Samudera Hindia yang terletak di antara Pulau Timor yakni Timor, Timor Leste dan Indonesia di sebelah utara dan Australia Utara di sebelah Selatan, sedangkan sebelah timur berbatasan dengan Laut Arafura yang secara teknis merupakan perpanjangan dari Samudera Pasifik Laut Timor. Pencegahan tersebut dapat menggunakan kemampuan pengawasan Polisi Maritim Timor Leste, (Unidade Policia Maritima UPM), Forças de Defesa de Timor Leste NAVAL (F-FDTL).

b) Strategi Preventif dan Responsif melalui Sarana dan prasarana

Teknologi Sisitem Monitorining Kapal. Salah satu upaya pengawasan dari pihak kementrian pertanian dan perikanan (Ministério da Agricultura e Pescas, liu husi Secretariado Estado das Pescas), dengan adanya bantuan dari Regional Fisheries Livelihood Programme (RFLP-FAO) yang sudah memasang SPOT TRACKER di dua kapal industri perikanan dan kapal ikan sejumlah 14 kelompok (peska artesanal hamutuk unidade 14 iha teritoriu Timor-Leste). Lihat peta dibawah ini.

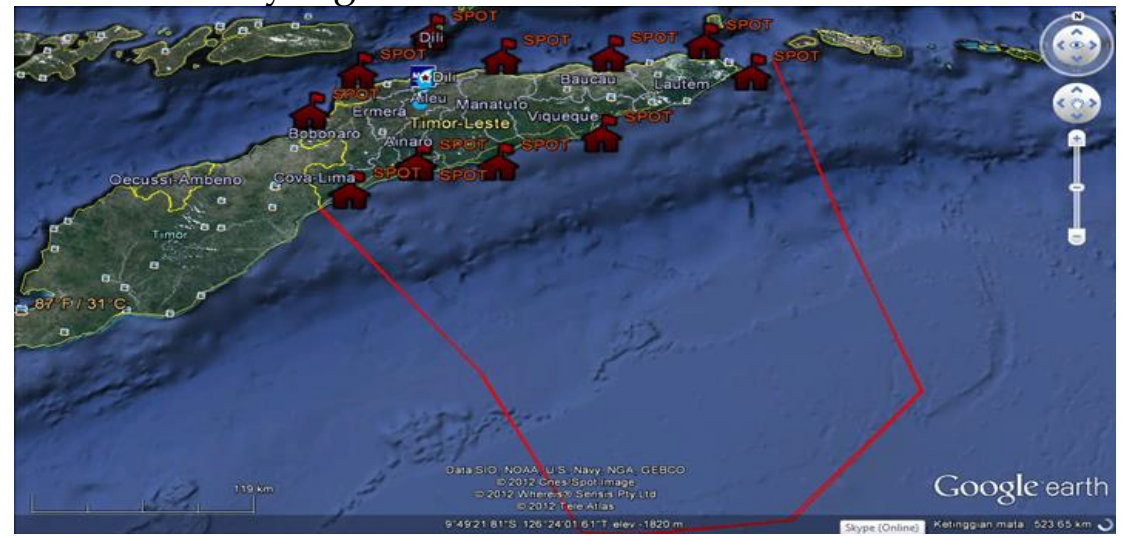

Gambar : 2. peta lokasi Satellite Personnal Tracker (SPOT)

Pada kenyataannya, tanpa Satellite Personnal Tracker (SPOT) akan kekurangan informasi tempat lokasi terjadinya IUU Fishing. Satellite Personnal Tracker (SPOT) berguna untuk mendeteksi kapal yang sudah mendapatkan izin agar tidak melanggar aturan-aturan yang telah ditetapkan dengan batasan-batasan pencarian ikan. Satellite Personnal Tracker (SPOT) sebagai cara untuk transmisi informasi dimana ada kegiatan illegal fishing itu terjadi dan juga 
menginformasikan ketika ada kapal yang berlayar diperairan laut Timor Leste mengalami kecelakaan. Namun Satellite Personnal Tracker (SPOT) yang sekarang digunakan belum memenuhi standar untuk ukuran perairan Laut Timor Leste.lihat gambar dibawah ini

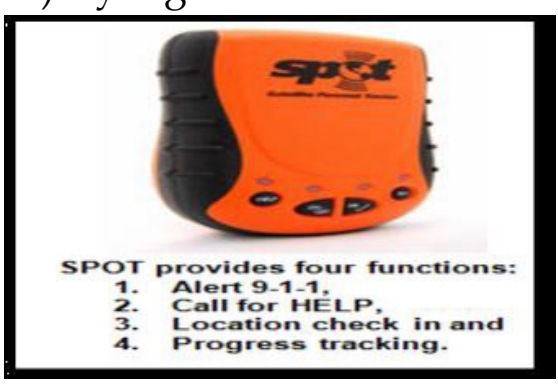

Gambar 3 Satellite Personnal Tracker (SPOT)

Keterbatasan armada penangkap ikan nasional menyebabkan fishing ground didominasi oleh kapal-kapal penangkap asing yang beroperasi di Zona Ekonomi Eksklusif Timor Leste. Sampai saat ini kementrian pertanian dan perikanan (Ministério da Agricultura e Pescas) belum mempunyai kapal pengawas untuk melakukan penegakan hukum dilaut dan hanya saling kordinasi dengan Polisi Maritim (Unidade Policia Maritima UPM), dan Forças de Defesa de Timor Leste NAVAL ( F-FDTL) untuk melakuakan penegakan hukum dilaut.

Beberapa kegiatan yang dilakukan oleh Polisi Maritim Unidade Policia Maritima (UPM) dan angkatan laut Forças de Defesa de Timor Leste NAVAL ( F-FDTL) dalam rangka mengamankan dan mengelola pulau terluar, antara lain :

1. Patroli Keamanan Laut

Patroli Keamanan Laut Timor Leste menghadirkan kapal-kapal Patroli yang dimiliki oleh Polisi Maritim Unidade Policia Maritima (UPM) dan angkatan laut Forças de Defesa de Timor Leste NAVAL (F$F D T L)$ di seluruh perairan wilayah
Timor Leste, termasuk di dua pulau terpencil, untuk melaksanakan patroli rutin dalam rangka penegakan keamanan di laut, juga dimaksudkan untuk menunjukan kesungguhan negara Timor Leste dalam mempertahankan wilayah maritmnya.

2. Operasi Pengamanan Perbatasan

Timor Leste memiliki perbatasan darat dengan Indonesia dan perbatasan laut dengan dua negara yaitu Indonesia dan Australia. Wilayah perbatasan maritim merupakan garis pertahanan Timor Leste yang memiliki potensi kerawanan dari segala bentuk ancaman sehingga membutuhkan perhatian yang serius.Terkait dengan pengamanan perbatasan, Polisi Maritim Unidade Policia Maritima (UPM) dan angkatan laut Forças de Defesa de Timor Leste NAVAL ( FFDTL) telah menempatkan sejumlah post di semua distrik atau wilayah Teritorial Timor Leste (Postu Batugade, Atabae, Atauro, Beloi, portaun portu Dili, sional 
Dili no postu Com Lospalos), servisu iha ró (ró NRTL Lusitania, NRTL Dili, NRTL Hera, NV TimorLeste, speed boat 12), no servisu iha kuartel Polisi Maritim Unidade Policia Maritima (UPM). https://www.pntl.tl/operasaun/ maritima/ Patroli dilaksanakan di sepanjang perbatasan darat serta melaksanakan operasi pengamanan perbatasan laut sepanjang tahun. Operasi pengamanan perbatasan laut disamping dilakukan secara unilateral juga dilaksanakan secara bilateral dengan negara terkait melalui Patroli Terkoordinasi (Coordinated Patrol). Data diambil di UPM di Sional, Dili Timor Leste, 2018.

\section{Kesimpulan}

1. Dalam rangka melaksanakan hak berdaulat, hak-hak lain, yurisdiksi dan kewajibankewajiban, aparatur penegak hukum Timor Leste yang berwenang, dapat mengambil tindakan-tindakan penanganan hukum sesuai dengan Hukum acara pidana Timor Leste Código Do Processo Penal bagian III mengenai Pasal 17 (1) dimana kejahatan dilakukan di atas kapal atau pesawat terbang yang mengatakan bahwa kejahatan yang dilakukan di atas kapal atau di pesawat, pengadilan di wilayah tersebut yang mengadili pelaku tidak pidana dan Kitab Undang-undang hukum Pidana Timor Leste Pasal 219 (1) mengatakan bahwa Penangkapan ikan ilegal adalah mereka yang

Jurnal Komunikasi Hukum (JKH) Universitas Pendidikan Ganesha

\section{Daftar Pustaka}

menangkap ikan di perairan maritim nasional tanpa izin dimana penangkapan ikan yang layak yang diperoleh dari otoritas administratif yang kompeten akan dihukum dengan hukuman penjara hingga 3 tahun

2. Melalui strategi preventive pencegahan pelayaran kapal asing di perairan terluar dengan efek pencegahan. Dalam artian, operasinya dikonsentrasikan pada perairan potensial yang rawan dari ancaman kedaulatan, antara lain Selat Ombai, selat Wetar dan laut Timor. Pencegahan tersebut dapat menggunakan kemampuan pengawasan Polisi Maritim Timor Leste, (Unidade Policia Maritima UPM), dan tentara nasional Forças de Defesa de Timor Leste NAVAL ( F-FDTL), serta dengan menggunakan strategi preventif dan responsif melalui Sarana dan prasarana teknologi sisitem monitorining kapal. Salah satu upaya pengawasan dari pihak kementrian pertanian dan perikanan (Ministério da Agricultura e Pescas, liu husi Secretariado Estado das Pescas), dengan adanya bantuan dari Regional Fisheries Livelihood Programme (RFLP-FAO) yang sudah memasang SPOT TRACKER di dua kapal industri perikanan dan kapal ikan sejumlah 14 kelompok di seluruh wilayah Timor Leste. 


\section{Buku}

Peter Mahmud Marzuki, Penelitian hukum, Kencana, Jakarta, 2005, Theo Huijbers, Filsafat Hukum dalam Lintasan Sejarah, Kanisius: Yogyakarta, 1982

\section{Undang- undang}

Konstituisaun Repúblika

Demokrátika Timor-Leste (RDTL 2002)

Código Do Processo Penal (Kitab Undang-undang Hukum Acara Pidana)

Código Penal Kodiku Penal (Kitab Undang-undang Hukum Pidana),2009

Lei No.12/2004 loron 29 fulan Dezembru "Krime Relativu ho Peska" Republica Democratica de Timor Leste. Ministerio da Agricultura e Pescas. Lei No.12/2004" Krime Relativu ho Peska"

República Democrática De TimorLeste Dekretu - Lei Governu N. ${ }^{\circ}$ 6/2004 21 Abril 2004 Baze Jeral Rejime Jurídíku Ba Jestaun Ho Ordenamentu Peska Ho Akikultura Nian 2004

República Democrática De TimorLeste Parlamento Nacional, Lei N.O 7/2002 De 20 De Setembro Fronteiras Maritimas do Territorio da Republica

Democratica De Timor-Leste

Knar Geral Policia Nasional Timor Leste E Lei Organiku (Decreto Lei No.09/2009

\section{Internet}

http:/ / www.kemlu.go.id/dili/id/be rita-agenda/infopenting/Pages/Profil-Negara-Timor Leste.aspx http://www.wallacea.org/jenisbaru-ikan-laut-pertama-di-timorleste.html.
https://id.wikipedia.org/wiki/Selat_ Wetar

https://www.pntl.tl/operasaun/mar itima/

http://timor-

leste.gov.tl $/ p=547 \&$ lang $=$ tp , diakses pada tanggal 26 juli 2017.WTL

http://www.kemlu.go.id/dili/id/be rita-agenda/infopenting/Pages/Profil-NegaraTimor-Leste.aspx, diakses pada tanggal 28 Juli 2017.WTL

http://www.republika.co.id/berita/i nternasional/abc-australianetwork/17/09/15/owbhap415 -15-kapal-cina-muat-ribuanekor-hiu-ditangkap-di-timorleste. Diakses pada tanggal 18 september 2017

Laporan Fundasaun Mahein (Mahein Nia Lian Nú 69, 13 Fevereiru 2014) data didapat dari departemen Ministériu Agrikultura no Peska tinan 2013 Timor-Leste Lakon Ninia Ikan. Di akses pada tanggal 27 november 2015. https://timordata.info/media/public ations/FM_MNL_69.pdf 